\title{
Operant conditioning of the skin resistance response with different intensities of light flashes
}

\author{
WILLIAM A. GREENE and HARRY G. WIRTH \\ Eastern Washington State College, Cheney, Washington 99004
}

\begin{abstract}
Operant conditioning of the skin resistance response was obtained using a dim flash of white light as the reinforcing stimulus. The results confirm earlier reports using similar procedures from another laboratory, show no differential effect of the illuminance of a reinforcing light, and contrast sharply with a study which failed to replicate previous studies using light flashes as the reinforcer. Assessment by postsession questionnaire yielded little evidence for awareness of the contingency relationship.
\end{abstract}

Kimmel (1967) and his associates have reported several studies in which the unelicited skin resistance response (SRR) was operantly conditioned. In several of these studies the positive reinforcer was a flash of dim, white light. Mandler, Preven, and Kuhlman (1962) using a red light and Stern, Bales, and Dionis (1966) using money as reinforcers reported negative results when attempting to operantly condition the SRR. Stern (1967), attempting to replicate the Kimmel procedures, used Van Twyver and Kimmel (1966) as a model study and also reported failure. Therefore, Stern correctly questioned the reliability of the conditioning effects reported by Kimmel and his associates.

The reliability of a phenomenon varies directly with the similarity between the conditions under which successive measures are made. Our analysis of the Stern and Van Twyver and Kimmel procedures revealed that Stern's replication was inexact. First, Stern ran two Ss simultaneously in the same soundproof room. Each S was aware of the other's presence. Kimmel's procedure entails only one $\mathrm{S}$ in the conditioning chamber. If two Ss are run concurrently, they are placed in separate chambers and are unaware of the other's presence. Second, Stern used a $1.3-\mathrm{cm}$ square of dim light, $.36 \mathrm{fc}$ illuminance, mounted $30.5 \mathrm{~cm}$ in front of $S$ as the reinforcing stimulus. Van Twyver and Kimmel (1966) placed the same size and intensity light $81.2 \mathrm{~cm}$ from $\mathrm{S}$. Although both studies used light of the same illuminance, the light used by Stern lacked the attenuation afforded by the greater distance in the Van Twyver and Kimmel experiment.

The implication of the Stern study was that the positive results reported by the Kimmel laboratory must be suspect. Therefore, we attempted to replicate Kimmel's procedures more exactly and to assess the effect of the intensity of the light on the conditioning process. In this manner we hoped to determine if positive outcomes are limited to one laboratory.

\section{METHOD}

\section{Subjects}

Thirty-six male and 36 female volunteer undergraduates from introductory psychology classes at Eastern Washington State College served as Ss. All Ss received extra class credit for participation.

\section{Apparatus}

$S$ sat in an upholstered chair in a soundproof chamber. The chamber was completely dark when the door was closed. S wore a sound-attenuating headset to further reduce extraneous noise. The SRR was picked up by two zinc electrodes, $2.1 \mathrm{~cm}$ in diam, seated in Lucite cups filled with electrode paste and strapped to the palm and back of the left hand. Skin resistance changes were detected and amplified by a Fels Dermohmmeter modified for constant output of 38 microA through S. SRRs were recorded on an ink-writing milliammeter. The reinforcing stimulus was a $.1-\mathrm{sec}$ light flash, $1.3 \mathrm{~cm}$ in diam, located $81.2 \mathrm{~cm}$ in front of $\mathrm{S}$. A variable, neutral density filter in front of the light was used to produce a light intensity of $.25, .50$, or $1.00 \mathrm{fc}$. Light intensities were calibrated with a MacBeth Illuminometer.

\section{Design}

The experimental plan was basically a 2 by 3 factorial. Ss received the light in one of two ways, either contingent $(C)$ upon each criterion SRR or noncontingent (NC), i.e., only when no SRRs were occurring. The other variable, at three levels, was light intensity. The first $S$ to arrive at the laboratory was randomly assigned one of the three light intensities in the $\mathrm{C}$ condition. The second $\mathrm{S}$ was automatically assigned to the NC group at the same light intensity as his/her $\mathrm{C}$ partner. Each successive $S$ was assigned in a similar manner with the following restrictions: like sexes were paired, an equal number of males and females were required in each cell, and each of the six cells was assigned an $\mathrm{S}$ before a new replication began.

\section{Procedure}

Each S was seated in the chair and electrodes attached. Ss were told to sit quietly, remain alert, keep their eyes open, and pay attention to what happened. The sound-attenuating headset was put on and the chamber door closed. The session was divided into three periods: 10-min habituation, 16-min reinforcement, and 10 -min extinction. During habituation, no stimuli were given and S's base rate of SRRs was taken. During reinforcement in the $C$ group, the light was flashed for each SRR that reached or exceeded 500 ohms. Each NC S received the same number of lights/min as his/her "yoked" partner, but only in the absence of SRRs. For all Ss, a "grace" period of $5 \mathrm{sec}$ followed each light during which no SRRs were counted. During extinction, no lights were given but recording continued. At the end of the session, Ss were asked: (1) What do you think caused the light to come on? (2) Did the lights appear to be affected by any thing you did or thought?

\section{RESULTS AND DISCUSSION}

To determine if the groups were comparable before conditioning began, response frequencies during the last 2 min of habituation were examined for all six groups. Analysis of variance on the transformed scores $R+1$ 
(where $\mathrm{R}$ is the number of responses emitted during the last $2 \mathrm{~min}$ of habituation) produced no significant differences $(F=1.00, \mathrm{df}=5 / 54)$.

The dependent measure used for the remaining analyses was the same as used by Stern (1967) and Van Twyver and Kimmel (1966). This measure was $\sqrt{(\mathrm{X}+1)}$ $\div(\mathrm{R}+1)$, where $\mathrm{X}$ is the frequency of SRRs emitted during each 2-min block of habituation, acquisition, and extinction and $R$ is the SRR frequency during the last $2 \mathrm{~min}$ of habituation. The transformed frequencies for all groups over 2-min blocks are presented in Fig. 1 for acquisition and extinction. The acquisition curves show an apparent separation between the contingency conditions over time but no difference attributable to light intensity emerged. The overall average for the transformed frequency scores during acquisition for each group was: C $1.25=1.05$, C $.50=1.00, \mathrm{C} 1.00=1.09$, $\mathrm{NC} .25=.87$, NC $.50=.83$, and $\mathrm{NC} 1.00=.93 \mathrm{~A}$ complete analysis of variance of the 2 by 3 table over 2-min blocks during acquisition showed that only the contingency effect, $\mathrm{C}$ vs NC, was significant, $\mathrm{F}=4.90$, df $=1 / 54, \mathrm{p}<.05$. The extinction data appear to be influenced by contingency of reinforcement but, as with the $\mathrm{C}$ condition, not by light intensity. The overall average for the transformed frequency scores during extinction were: C $.25=.99$, C $.50=1.03$, C 1.00 , = 1.26 , NC $.25=1.03$, NC . $.50=.97$, and NC $1.00=1.01$. A complete analysis of variance failed to support any of the apparent differences. A t test between each $\mathrm{C}$ and $\mathrm{NC}$ condition at each light intensity indicated that only the difference between $\mathrm{C} 1.00$ and $\mathrm{NC} 1.00$ was significant, $\mathrm{t}=2.48, \mathrm{df}=18, \mathrm{p}<.05$.

The results of the present study conflict with those of Stern (1967) in that the flash of a dim light was shown to act as a positive reinforcer for the unelicited SRR. Thus, at least one other laboratory has shown positive results with this reinforcer.

Since we obtained only a slight indication of any difference between conditions during extinction, our

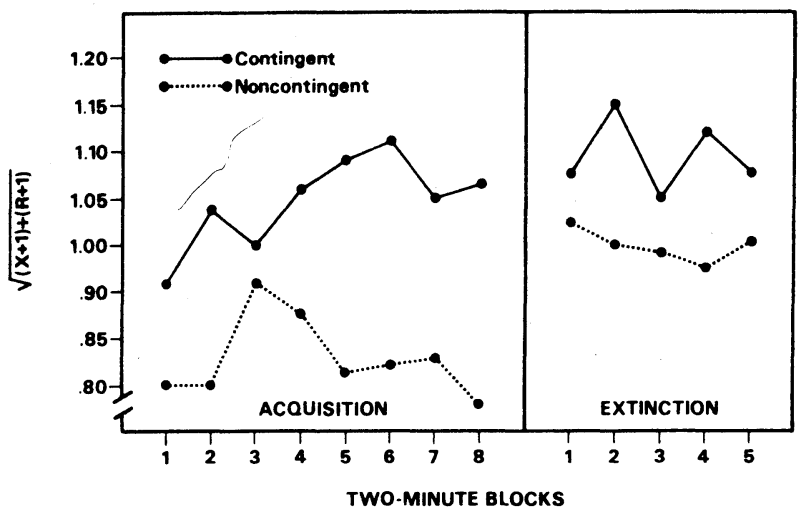

Fig. 1. Mean transformed response frequency rates for the contingent and noncontingent reinforcement groups with $10 \mathrm{Ss}$ in each group. results only partially support two of the earlier Kimmel studies (Kimmel \& Kimmel, 1963; Van Twyver \& Kimmel, 1966) which reported significant effects during that same period.

Accordingly, then, this study and the previous studies (Kimmel, 1967) have provided sufficient evidence to establish the reinforcing capabilities of a dim white light. It appears, however, that even at best it is a weak reinforcer. In the successful studies cited above, the present study included, the behavioral effects accruing from the use of light as a reinforcer have been small. None of these studies have reported large changes in response rate or strong resistance to extinction. In addition, it appears that even a slight deviation from the successful procedure established by Kimmel and his colleagues, i.e., placing two Ss in the same room such that they are aware of one another's presence, seems to alter the experimental environment sufficiently to disrupt the conditioning process. It does not appear, however, that the brightness of the light, at least within the range used here, is a significant variable. Since the time of the Stern publication, other studies have been reported successfully using a variety of reinforcers of unelicited electrodermal activity (Kimmel, 1973). Some of these stimuli have resulted in stronger and/or more lasting conditioning effects. Unless the E's interest lies in investigating light per se as a reinforcer, the use of these stronger reinforcers is recommended.

The results of our questionnaire data indicated that only one $\mathrm{S}$, in the $\mathrm{C}$ group, expressed any relationship between his behavior and the light. All others simply responded with "I don't know" type statements. This contrasts with Stern's study, where no conditioning was obtained and in which 13 out of $16 \mathrm{Ss}$ in the C group reported that their "responding" was somehow tied to the light, while 13 out of $16 \mathrm{Ss}$ in the NC group reported that their "relaxing" was tied to the light. The reason for the discrepancy is not apparent. It is interesting to note, however, that Ss in the Kimmel laboratory seldom report awareness of the contingencies yet their SRRs condition readily. Finally, Greene and Nielsen (1966) found that low autonomic perceivers but not high autonomic perceivers increased SRR frequency for contingent points on a counter, emphasizing the inverse relationship between conditioning and awareness.

\section{REFERENCES}

Greene, W. A., \& Nielsen, T. C. Operant GSR conditioning of high and low autonomic perceivers. Psychonomic Science $1966,6,359-360$.

Kimmel, E., \& Kimmel, H. D. A replication of operant conditioning of the GSR. Journal of Experimental Psychology, 1963, 65, 212-213.

Kimmel. H. D. Equating stimulus intensities by means of the GSR. Psychonomic Science, 1967, 7, 77-78.

Kimmel, H. D. Instrumental conditioning. In W. Prokasy and D. Raskin (Eds.), Electrodermal behavior. New York: Academic Press, 1973. Chap. 5, pp. 255-282.

Mandler, G., Preven, D. W., \& Kuhlman, C. K. Effects of operant reinforcement on the GSR. Journal of the Experimental 
Analysis of Behavior, 1962, 5, 17-321.

Stern, R. W., Bales, J., \& Dionis, J. Operant conditioning of spontaneous GSR's: Two unsuccessful attempts. Technical Report No. 13, 1966, Indiana University, Contract Nonr 908-15, Office of Naval Research.

Stern, R. M. Operant conditioning of spontaneous GSR's: Negative results. Journal of Experimental Psychology, 1967, 75, 128-130.
Van Twyver, H. B., \& Kimmel, H. D. Operant conditioning of the GSR with concomitant measurement of two somatic variables. Journal of Experimental Psychology, 1966, 72, 841-846.

\title{
Pharmacological modulation of photically evoked afterdischarge patterns in hooded Long-Evans rats
}

\author{
ERIN D. BIGLER and DONOVAN E. FLEMING \\ Brigham Young University, Provo, Utah 84602 \\ and \\ DONALD E. SHEARER \\ Neuropsychology' Research Laboratories, Veterans Administration Hospital \\ Salt Lake City, Utah 84113
}

\begin{abstract}
The pharmacological modulation of photically evoked afterdischarge (AD) patterns within a short-term habituation paradigm were examined in the hooded Long-Evans rat. Pharmacological arousal by amphetamine, pilocarpine, and physostigmine or induced thalamic suppression by trimethadione (Tridione) attenuated $\mathrm{AD}$ development. $\mathrm{AD}$ development was unaffected by saline, methyl atropine, and atropine. Pentylenetetrazol (Metrazol) was used as an AD potentiator and, as such, enhanced AD development following all drug conditions except within the physostigmine and methyl atropine sessions. It was determined that in the hooded rat $\mathrm{AD}$ varies only as a function of drug injected; time (habituation) was not a factor. The role of the reticulocortical projection system and the limbic system was incorporated in the explanation of the results. Significant differences were also noted between the pharmacology of AD parameters in hooded vs albino rats.
\end{abstract}

Iterative stimulation by single photic pulses evokes electrocortical bursts of rhythmic afterdischarges (ADs) in the primary visual cortex of the rat (Fleming, Rhodes, Wilson, \& Shearer, 1972, 1973; Fleming, Wilson, \& Shearer, 1973; Fleming Shearer, \& Creel, 1974; Rhodes \& Fleming, 1970; Shearer, Fleming, Bigler, \& Wilson, 1974). In albino rats, this sinusoidal afteractivity is suppressed through pharmacological stimulation by adrenergic (amphetamine), cholinergic (pilocarpine, physostigmine), and thalamically active anticonvulsant drugs (Fleming et al, 1972, 1974; Shearer et al, 1974).

In correlated research, Fleming et al (1973) have demonstrated that $\mathrm{AD}$ total excursion (TE) patterns in hooded rats were at variance with those patterns evinced by albino rats. Two major differences were noted: (1) $\mathrm{AD}$ values for hooded rats were of a significantly lower magnitude than those recorded for albino rats, and (2) hooded rats did not display the characteristic initial increase and subsequent decrease in $\mathrm{AD}$ TE consistently observed as a function of time in the albino rat (Rhodes \& Fleming, 1970). For the hooded rat strain, AD TE remained constant over time. These results were accounted for partially by potential differences in the receptive properties of the two visual systems. In terms of this interpretation, Creel, Dustman, and Beck (1970) have reported significant differences in visually evoked responses (VERs), which were related to anatomical differences in the visual systems of albino and hooded rat strains (cf. Lund, 1965).

Since there are between-strain differences in response to pharmacological arousal per se (Fuller, 1970; Meier, Hatfield, \& Fushee, 1963), as well as the marked differences in VER and AD TE parameters between hooded and albino rat strains, the question arises whether $\mathrm{AD} \mathrm{TE}$ in the hooded rat in response to pharmacological modulation is in the same direction and of the same magnitude as that already established in the albino rat (Fleming et al, 1972, 1974; Shearer et al, 1974). Thus, the intent of the present investigation was to determine systematically the effects of pharmacological arousal or induced thalamic abatement on $\mathrm{AD}$ TE in the hooded Long-Evans rat strain. The following report was a direct procedural replication of 